\title{
Research on the Theoretical Basis and Technical Path of Predictive
}

\section{Policing}

\author{
LENG Jing ${ }^{1, a}$, Li Guojun 2* \\ ${ }^{1}$ Department of Information Technology, Hubei University of Police, Wuhan, China \\ $2^{*}$ Corresponding author, Department of public security management, Hubei University of Police, \\ Wuhan, China
}

aemail:daleng0127@sina.com

Keywords : Crime analysis; Crime forecasting; Crime prevention; Policing strategy; Policing innovation; Predictive policing; Big data

Abstract. Development of rational choice theory, routine activity theory, crime pattern theory and environmental criminology, criminal geography and other criminology theories laid the theoretical foundation of crime forecasting. Advances in technology enhance the reliability and accuracy of crime forecasting, such as statistics theory, data science, computational science and geographic information system technology. Based on Intelligence-led Policing, police department applied crime forecasting for resource allocation and service planning, emphasizing on more proactive intervention to prevent and control crime. Predictive policing strategy emerged gradually. Its effectiveness has been verified in multinational police practice. Our Police Geographic Information System and public security intelligence system contain some crime forecasting and warning functions. Some local public security units have carried out crime forecasting to proactive policing practices in recent years, which has obtained good results. Predictive policing is consistent with the actual demand of our police work, and it can promote the Intelligence-led Policing. Its development path and experience provide reference resources for the crime prevention and policing innovation in our country.

\section{Introduction}

In recent years, under the impetus of the development of the related theories of criminology, relying on the progress of quantitative forecasting technologies, such as police geographic information technology, computer statistics, and crime mapping, especially big data technology, some national police departments lead the police work with crime prediction, which greatly improves the effect of police intervention and crime prevention. On this basis, a new policing strategy named "predictive policing" has been developed. The predictive policing driven by big data is an important direction of police innovation in the future.

\section{The Development of the Theory of Crime Prediction}

The development of the related theories of criminology such as rational choice theory, daily activity theory, crime pattern theory, environmental criminology and criminal geography has laid the theoretical foundation for crime prediction.

In the traditional crime deterrence theory, the "punishment-deterrent" model implied the content of the criminal's "cost—benefit" consideration of the crime. The view of law and 
economics of Posner regards crime as a rational choice, which is a choice after the trade-off between cost and benefit. The crime is not completely random but based on the rational choice of the perpetrator. If we can predict the criminal behavior and implement targeted police intervention to raise the cost of crime, even if the risk of being arrested increases just due to the arrival of the police, the offender may abandon the implementation of the crime based on rational calculation. The empirical study of the theory of deterrence shows that the deterrent effect of the police on crime is significant. Increasing the rate of arrest will greatly increase the cost of crime and then create the deterrent force. Service activities such as patrols will deter and prevent crime, especially the increase of the police duty has a strong deterrent effect on street crime. [1]

The theory of daily activity holds that the behavior of the criminal follows the day-to-day pattern of time and space, so that its behavior pattern has a certain repeatability and predictability.[2] Felson believes that the successful implementation of crime is the result of three factors: "motivated criminals, appropriate target of infringement, and lack of effective guardians". If environmental factors make crime easy to succeed and avoid being punished, the motivated criminal will commit crimes at suitable locations for appropriate target. According to the idea of crime prevention based on "location", the location itself is not the cause of crime. It only provides goals and opportunities for the implementation of crime, and improves the risk and possibility of a certain crime.[3] Some places with high crime concentration do not exist more infringed targets or more potential criminals, but their environmental conditions are more likely to be more successful than others in the implementation of crimes, which attracts more criminals. The appropriate practice is to deploy the police in places where the perpetrators are attracted and the risk of the crime is higher.

The theory of crime pattern combines the theory of rational choice and the theory of daily activity to explain the distribution of crime in space. It is believed that the interaction between the criminal and its natural and social environment affects the choice of the crime target. In daily activities, the criminal will pay attention to those places that lack protection and management based on rational choice. Crime occurs in the perceived space of the offender, which is related to the appropriate infringement target. Therefore, the temporal and spatial distribution of different crimes is neither random nor different, and the occurrence of criminal acts follows a specific pattern.[4]

There are different limitations in rational choice, daily activities and crime pattern theory, which lack convincing explanation for social relational crime and sudden violent crime. It is also difficult to explain the behavior differences between different individuals in the same daily activities. Even so, these theoretical studies turn the focus of crime prevention from "man" to "place". On the one hand, it promoted the development of environmental criminology and criminal geography, produced strong operative situational crime prevention theory, environmental design and crime prevention theory, and achieved good results in the practice of crime prevention. On the other hand, it promoted the transformation of community policing and problem oriented policing, and emphasized that the police should work with the community and the public to focus the crime prevention on the solution of specific problems in the community, and prevent and reduce crimes in many ways.

\section{Crime Prediction Technology Driven by Big Data}

The content of the crime prediction mainly includes four aspects: the type of crime and the prediction of the time and space, criminal prediction, the prediction of the recidivism and the prediction of the victim. Traditional crime analysis usually includes statistical analysis, crime mapping, comparison of artificial tabulation, monitoring and information analysis for key areas and suspicious personnel, etc. The size of the data it needs is small, and it is limited to the scope of the 
area. It is mainly based on the experience of experts to make a prediction. Prediction analysis relies on larger volume data, including both internal data collected by police and the related external data, and it also pay attention to the mining for the potential value of data. Prediction analysis does not exclude traditional analysis methods, however, its mathematical models and algorithms are more complex, manual computation is difficult to achieve, and personal preferences lead to smaller errors. Crime prediction from experience to science relies on the introduction and development of many scientific methods, such as statistical science, data science and computational science, especially information technology and crime analysis technology based on GIS. Commonly used prediction analysis methods, as shown in Table 1, mainly include crime hot spot mapping analysis, regression analysis, data mining, spatio-temporal analysis and other analysis methods based on criminal historical data and geographic information.[5] The type of data size, process, and algorithm complexity are different for different analysis methods. Each analysis method has its scope of application and certain limitations.

Tab. 1 Common prediction analysis method

\begin{tabular}{|c|c|}
\hline Analysis type & Analysis method \\
\hline Crime hot spot drawing & $\begin{array}{c}\text { Grid chart, elliptical overlay graph, kernel density } \\
\text { analysis, heuristic method }\end{array}$ \\
\hline Regression analysis & $\begin{array}{c}\text { Linear regression, stepwise regression, spline regression, } \\
\text { leading index method }\end{array}$ \\
\hline Data mining & Cluster analysis and classification analysis \\
\hline Spatiotemporal analysis & Thermal analysis, additive model, seasonal analysis \\
\hline Near repeat & Self-excited process algorithm, PROMAP, heuristic \\
& method \\
\hline Risk region analysis & Risk region modeling and spatial prediction analysis \\
\hline
\end{tabular}

\section{The Practice of Predictive Policing}

Community policing and problem-oriented policing have achieved remarkable results in terms of public participation in crime prevention and police participation in social services. However, there is a real need for the return of policing to traditional prevention and combating crime targets. In the 1990s, the New York Police Force in the United States started to carry out intelligence-led policing reform. Intelligence information has become the core factor in police decision-making and emphasized early warning and intervention in criminal behavior. [6] The successful trial of crime maps based on early artificial markers resulted in a tremendous success when the New York Police Department started running the CompStat project in 1994, and the nationwide policing department began promoting crime mapping and data-driven management in 1998. Driven by the development of information technology and geographic information technology, the intelligence-led policing strategy makes the policing resources allocation and service planning more reasonable and policing more focused and becomes the policing strategy choice of many countries.

Advances in crime prediction technology have taken a big step forward in the initiative, reliability and accuracy of intelligence-led policing and have yielded good results in policing practice. The practical application of predictive policing comes from the small pilot projects carried out by a number of urban policing departments in cooperation with universities, technology companies and others. The success of these projects has gradually attracted the attention and funding at the national level. In 2008, the Los Angeles Police Department began working closely with Bureau of Justice Assistance and National Institute of Justice to explore new concepts in 
predictive policing and its application in law enforcement. In the practice of police departments around the world, the predictive policing strategy has been gradually accepted in the policing departments of the United States, Britain and Canada. Predictive techniques and more active police intervention have been further developed.

Almost in sync with the descriptive policing changes in western countries, since 2007, the construction and operation of the police geographic information system (PGIS) and the public security "big intelligence" system have become the boosters for the development of policing in China in recent years. They have carried out a wide range of application and promotion in various public security businesses and have achieved remarkable results in application. [8] The crime prediction based on PGIS and big intelligence system mainly focuses on the aspects of crime mapping based on GIS, crime hot spot analysis, statistical analysis of space-time distribution and so on. At the same time, some new analytical methods are gradually introduced into the field of crime analysis and prediction, such as the Analytic Hierarchy Process (AHP) of crime probability model based on GIS integration and the crime prediction technology based on Agent Based Model to predict the transfer tendency of criminal hot spots in time and space. [10] Some local public security organs have realized that the prediction leads the policing work and conducts a small-scale experimental exploration with remarkable results.

\section{Conclusions}

Predictive policing is the deepening impetus of the existing intelligence-led policing, but it is only a part of the crime prevention and control system and needs to be constantly revised and improved. The evaluation should take into account factors such as the input of police resources, funding, and public participation. If they are separated from scientific methods such as blind test, control and comparison, and historical analysis, their advantages are often magnified. Assessing the reliability and accuracy of predictions must take into account the projected time horizon and geographical extent. Excessive long-term projections have no practical value to the police. In terms of prediction categories and technologies, the existing predictive policing practice is more effective in prevention and control of multiple property-type cases such as theft, and it is more difficult to predict social-related crimes and violent crimes. Prediction technology methods are still under exploration. There are still technical bottlenecks in the collection, integration and value mining of a large number of unstructured, semi-structured and low-value-density social network data and a large number of multimedia data such as video and audio. More importantly, prediction is not the result of machine self-reflection. All prediction methods are designed by people and require some degree of human intervention and decision making. Human factors are always the ultimate determinants.

The operation of predictive policing must balance the relationship between the data collection and the protection of the rights of personal data and always put data security first. Prediction is not based on traditional evidence but based on data. Predicted people often have geographical, occupational, social or other commonalities. Police also have a definition of "high-risk criminals" in crime analysis, which may lead to the discriminatory use of first-mover interventions in practice, and trigger a range of negative conflicts and negative impacts.

\section{References}

[1]Chen Yili,Chen Gang. The theory and Empirical Study of the deterrent effect: past, present and future [J]. Research on Institutional Economics, 2009，25（3）: 169-185 
[2] Li Xihui,Liao Mei. A review of the contemporary western rational choice of Criminology [ J ] .Public Security Science Journal-Journal of Zheijiang Police College,2004,84(4):42-45

[3] Caplan JM.Mapping the Spatial Influence of Crime Correlates: A Comparison of Operationalization Schemes and Implications for Crime Analysis and Criminal Justice Practice [J] . CITYSCAPE, 2011, $13(3): 57-83$

[4] Hiropoulos A, Porter J.Applying GIS to Crime Pattern Theory [ J ] .South African Crime Quarterly, 2014, 47 (3) : 17-26

[5] Perry W L, McInnis B, Price CC, et al.Predictive Policing: The Role of Crime Forecasting in Law Enforcement Operations [R ] . National Institute of Justice, Office of Justice Programs, U.S. Department of Justice. No. 2010-IJ-CX-K007. Rand Corporation, 2013 